\title{
Prevalence of cognitive impairment in individuals aged over 65 in an urban area: DERIVA study
}

\author{
Emiliano Rodríguez-Sánchez ${ }^{*}$, Sara Mora-Simón", María C Patino-Alonso³, Ricardo García-García², \\ Alfonso Escribano-Hernández ${ }^{1}$, Luis García-Ortiz ${ }^{1}$, Ma Victoria Perea- Bartolomé ${ }^{2}$ and Manuel A Gómez-Marcos ${ }^{1}$
}

\begin{abstract}
Background: Few data are available on the prevalence of cognitive impairment (Cl) in Spain, and the existing information shows important variations depending on the geographical setting and the methodology employed. The aim of this study was to determine the prevalence of $\mathrm{Cl}$ in individuals aged over 65 in an urban area, and to analyze its associated risk factors.
\end{abstract}

Methods: Design: A descriptive, cross-sectional, home questionnaire-based study; Setting: Populational, urban setting. Participants: The reference population comprised over-65s living in the city of Salamanca (Spain) in 2009. Randomized sampling stratified according to health district was carried out, and a total of 480 people were selected. In all, 327 patients were interviewed (68.10\%), with a mean age of 76.35 years (SD: 7.33). Women accounted for $64.5 \%$ of the total. Measurements: A home health questionnaire was used to obtain the following data: age, sex, educational level, family structure, morbidity and functionality. All participants completed a neuropsychological test battery. The prevalence data were compared with those of the European population, with direct adjustment for age and sex. Diagnoses were divided into three general categories: normal cognitive function, cognitive impairment - no dementia (CIND), and dementia.

Results: The prevalence of $\mathrm{Cl}$ among these over-65s was 19\% (14.7\% CIND and 4.3\% dementia). The age-and sexadjusted global prevalence of $\mathrm{Cl}$ was $14.9 \%$. $\mathrm{Cl}$ increased with age $(\mathrm{p}<0.001)$ and decreased with increasing educational level $(p<0.001)$. Significant risk factors were found with the multivariate analyses: age $(O R=1.08,95 \%$ $\mathrm{Cl}: 1.03-1.12)$, anxiety-depression ( $\mathrm{OR}=3.47,95 \% \mathrm{Cl}$ : 1.61-7.51) and diabetes $(\mathrm{OR}=2.07,95 \% \mathrm{Cl}$ : 1.02-4.18). In turn, years of education was found to be a protective factor $(\mathrm{OR}=0.79,95 \% \mathrm{Cl}$ : 0.70-0.90). Although $\mathrm{Cl}$ was more frequent among women and in people living without a partner, these characteristics were not significantly associated with $\mathrm{Cl}$ risk.

Conclusions: The observed raw prevalence of Cl was 19\% (14.9\% after adjusting for age and sex). Older age and the presence of diabetes and anxiety-depression increased the risk of $\mathrm{Cl}$, while higher educational level reduced the risk.

\section{Background}

The prevalence of neurodegenerative diseases increases with age $[1,2]$. Considering that the Spanish population is among the oldest in the world (particularly the Autonomous Region of Castilla y León, where $22.5 \%$ of the inhabitants are aged over 65) [3], a substantial increase in the prevalence of cognitive impairment (CI) is to be expected in the coming years.

\footnotetext{
* Correspondence: emilianorodriguezsanchez@yahoo.es

'Primary care research unit of La Alamedilla Health Center, Castilla y León Health Service- SACYL, Salamanca, Spain

Full list of author information is available at the end of the article
}

It is difficult to estimate prevalence figures for CI, since the diagnostic criteria are imprecise [4,5]. Indeed, the published dementia prevalence data for both Spain $[2,6-8]$ and other European countries $[1,9,10]$ show great variation. Therefore, it is not possible at present to provide reliable figures applicable to our setting. Although direct age-adjusted comparisons have been made among the different study populations, there are other influencing variables with greater adjustment problems, such as the setting (rural-urban), living in the home or in institutions, the diagnostic criteria used [11], or educational level. Also, more recent attempts to 
reformulate the constructs propose a clinical spectrum of $\mathrm{CI}$ ranging from mild cognitive impairment through dementia and a corresponding physio-pathological substrate believed to be responsible for the clinical symptoms $[4,5]$. The analysis of interventions that may prove effective in preventing the problems associated with $\mathrm{CI}$ is generating much interest, since the established therapies applied to $\mathrm{CI}$ are scarcely effective. However, the data available on the prevalence of $\mathrm{CI}$ in Spain are even more limited than in the case of dementia, and show important variations depending on the geographical setting and the methodology employed.

The present study carry out to estimate the prevalence of $\mathrm{CI}$ in the urban population over 65 years of age in the city of Salamanca (Spain), and to describe the factors associated with $\mathrm{CI}$.

\section{Methods \\ Study design}

An observational, descriptive, cross-sectional population study.

\section{Setting}

The reference population was that of the city of Salamanca, with 172,375 inhabitants, of which $19.74 \%$ $(34,020)$ were aged over 65 . It includes 10 healthcare areas, each with a population of between 9,000 and 26,000 inhabitants.

\section{Participants}

We selected all those aged over 65 on 1 January 2009 and living in the city of Salamanca (urban setting). A door-to-door population-based survey was carried out during the months of May to November 2009. Two weeks before the interviews, letters were sent to the selected individuals, explaining the purpose of the study and requesting their cooperation. Confidentiality of data was guaranteed. Ten days after sending the letters, a telephone call was made to arrange a home interview.

\section{The following exclusion criteria were applied}

1) deceased individuals; 2) errors in address: a) when the letter was returned, or when the selected person or some reliable informer could not be located after 4 visits to the home or 4 telephone calls on different dates and at different times; b) persons who had moved out of the study area; and 3) those individuals who declined to participate in the study.

\section{Ethical aspects}

The protocol was approved by the Research Ethics Committee of Salamanca University Hospital. Participants signed the consent document after receiving the first explanatory letter providing information on the study.

\section{Training of the evaluators}

The principal researcher coordinated the entire process. The evaluators were four psychologists trained by one of the researchers (SMS) to carry out the interview with the programmed questionnaires. A manual was drafted, describing the appointment procedure and application of the interviews, and was reviewed with the interviewers over two sessions. We also used two recorded home interviews in the training sessions. During the study, communication was permanently maintained for resolving any doubts or dealing with incidents in relation to the questionnaires.

\section{Data sources}

The sample was taken from the Castilla y León Regional Health Service lists, which cover $99.5 \%$ of the population. The lists included both community dwellers and institutionalized elders.

\section{Study size}

Accepting an alpha risk of 0.05 and a beta risk of 0.20 , estimating a CI prevalence of about $16 \%$ [12], with an error of $4 \%$, and considering the current population aged over 65, a total of 320 patients was required. Assuming a loss rate of up to $50 \%$ due to nonresponses, as observed in similar studies, the calculated sample size was 480 individuals. In the secondary analysis of cases and controls, with a 327 participants sample, the statistical power was of $79.4 \%$ to detect an Odds Ratio of 2.5 with a confidence level of 95\% (Epidat 4.0). We carried out a stratified random sampling by health districts. In order to reach the required sample size, we made a replacement for lost participants. The sample size of each health district was proportional to its population over 65 years. In a first stage, 260 interviews were carried out, accounting for $80 \%$ of the required sample. Two months later, in a second stage, we replaced the losses within each health district and 67 more people were interviewed. The most common cause of losses was patient refusal to participate (83.0\%). This was particularly the case among the younger individuals (mean age: $75.94 \pm 7.01$ years $)(\mathrm{p}<0.001)$. In turn, 12 patients were excluded because they had moved out of the study district $(7.8 \%)$, while 14 had died (9.2\%) (Figure 1). There were no significant differences between sexes regarding the cause of losses, or between losses in the first and second recruitment stages. Non-responders represented $34.83 \%$ of the males and $30.13 \%$ of the females. The distribution by age groups is shown in Table 1. Mean age of the males was 76.61 years (SD: \pm 7.65 ), versus 77.52 years (SD: \pm 7.92 ) in the females. There were no differences in distribution between the different sex and age categories. A total of 327 participants were interviewed, representing $68.1 \%$ of those 


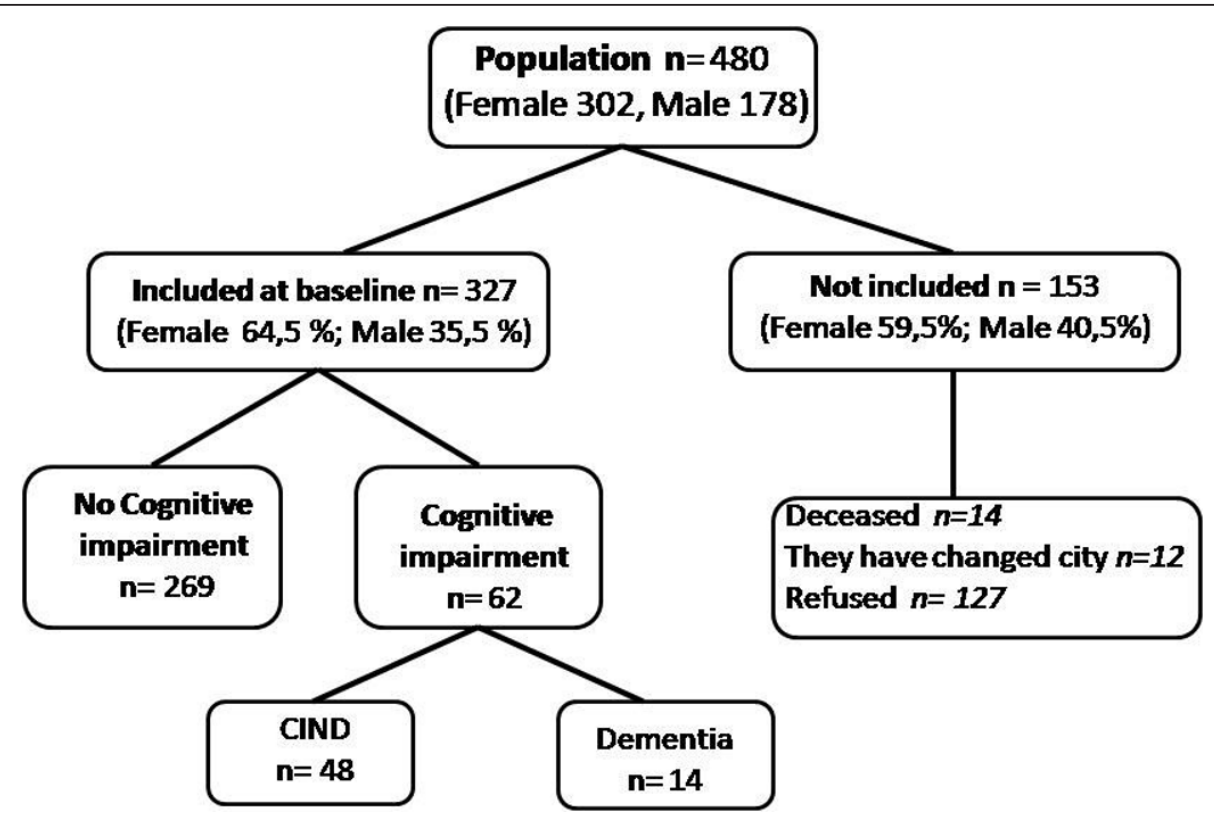

Figure 1 Flow chart of the DERIVA Study

selected (Figure 1). Of these, 116 were men (35.5\%) and 211 were women $(64.5 \%)$, with a mean age of 76.35 years (SD: \pm 7.33) similar in the two sexes.

\section{Measurements}

A health questionnaire was administered (OARS Multidimensional Functional Assessment Questionnaire) [13] in the participant's home, for obtaining data on sociodemographics (age, sex, marital status), years of education, basic and instrumental activities of daily living, personal situation (people living with the patient, number of living offspring), morbidity (Charlson comorbidity index [14]), drug use and neuropsychological aspects. Marital status was classified according to whether the person was living with or without a partner (widowed, single, separated), while educational level was classified as follows: illiterate (failure to complete basic education), primary-secondary education (4-9 years of education) and higher education (over 9 years). Regular professional occupation before retirement was defined as domestic chores, full-time job, others (part-time job, long-term unemployment, etc.). The Katz Index of Independence in Activities of Daily Living (Katz ADL) was applied to assess functional status as a measure of patient ability to perform activities of daily living (ADLs) independently [15]. This test provides information on dependence or independence, not only in terms of the number of areas, but also identifying the specific areas. The information obtained is of a qualitative and descriptive nature, and does not provide a total score on the person's functional state.

At the beginning of the interview, neuropsychological assessment of patient cognitive status was carried out using a brief neuropsychological test battery including the following: Mini-Mental State Examination (MMSE) [16] in its validated Spanish version [17] to evaluate general cognitive state, with the possibility of assessing cognitive functions separately; the 7 Minute

Table 1 Distribution according to gender and different age ranks of interviewed and lost sample population.

\begin{tabular}{|c|c|c|c|c|c|c|}
\hline \multirow[b]{2}{*}{ Age (years) } & \multicolumn{2}{|c|}{ Female $(\mathrm{N}=302)$} & \multicolumn{2}{|c|}{ Male (N = 178) } & \multicolumn{2}{|c|}{ Total $(\mathrm{N}=480)$} \\
\hline & Interviewed & Lost & Interviewed & Lost & Interviewed & Lost \\
\hline Mean (SD) & $76.64(7.64)$ & $77.52(7.08)$ & $75.81(6.73)$ & $76.61(7.65)$ & 76.35 (7.33) & $77.15(7.80)$ \\
\hline 65-69 (\%) & 21.3 & 17.6 & 20.74 & 19.4 & 21.1 & 18.3 \\
\hline $70-74(\%)$ & 21.8 & 20.9 & 22.4 & 25.8 & 22.0 & 22.9 \\
\hline $75-79(\%)$ & 20.4 & 25.3 & 27.6 & 21.0 & 22.9 & 23.5 \\
\hline $80-84(\%)$ & 19.5 & 17.6 & 19.0 & 14.5 & 19.3 & 16.3 \\
\hline$\geq 85(\%)$ & 17.1 & 17.1 & 10.3 & 19.3 & 14.7 & 19.0 \\
\hline Total: N (\%) & 211 (64.5\%) & 91 (59.5\%) & 116 (35.5\%) & 62 (40.5\%) & 327 (100\%) & 153 (100\%) \\
\hline
\end{tabular}


Screen [18] in its validated Spanish version [19] also to evaluate general cognitive state, as well as temporal orientation, memory, constructive praxias and language, separately; the Benton temporal orientation test [20] to evaluate temporal orientation; the Enhanced cued recall test [21] to evaluate episodic memory; the Clock drawing test [22] to evaluate constructive praxias; and the Categorical fluency task [23] to evaluate language. The cut-off points for cognitive impairment established for each test are as follows: MMSE $<24 ; 7 \mathrm{MS} \leq$ percentile 20; Benton temporal orientation test $\leq 102$; Enhanced cued recall test $\leq 12$; Clock drawing test $<3$; Verbal fluency $\leq$ 10.

During the structured interview, participants were asked to present whatever relevant clinical records they might have, together with details of their current medications. In the 16 patients who were unable to complete the neuropsychological evaluation because of a deteriorated clinical condition - heart failure (2 cases), deafness (4 cases), severely impaired vision (2 cases) or severe mental impairment (4 cases) - the clinical and objective data were collected from the presented documentation, or by interviewing the caregiver or informant who knew the individual. We considered as reliable informants, in order of preference, a family member living in the same house as the individual (spouse, son/daughter, sibling); a person responsible for the care of the individual; someone living in the same house but not a family member; or a relative of the person not living in the same house. At the end of the interview the interviewers drafted a report on the quality of the information collected and on the social and health conditions of the person interviewed. Seventeen participants lived in homes for the elderly (5.2\%). All the information was evaluated by the researchers (ERS, SMS, RGG and MVP) with a view to establishing the final diagnosis. The diagnoses were divided into three general categories: normal cognitive function, cognitive impairment - no dementia (CIND), and dementia.

\section{Classified as cognitive impairment - no dementia (CIND)} CIND was defined as: 1) mild cognitive or functional impairment reported by the participant or informant that did not meet criteria for dementia; or 2) performance on neuropsychological or functional measures that was both below expectations and $\geq 0.5$ standard deviations below published norms on any test [24].

\section{Classified as dementia}

A diagnosis of dementia was made based on the Diagnostic and Statistical Manual of Mental Disorders (IV Edition) criteria: the participant must present the development of multiple cognitive deficits including memory impairment and impairment in at least one other cognitive domain representing a decline from the previous level of functioning and of sufficient severity to cause impairment in function $[4,5]$. At a functional level, the person must present dependence in at least two functional areas, leading to interference in basic activities of daily living. Alterations at both the cognitive and functional levels were indicated by low performance and scores below the cut-off points in the neuropsychological and functional tests. As regards functional state, the person must present a minimum level of alteration in at least two functional areas. All of this must be accompanied by concern on the part of the participants about a change at a cognitive level compared to his or her previous state $[4,5,25]$.

\section{Statistical analyses}

The raw prevalence of CIND and dementia were calculated taking into account the total cases of CIND and dementia with respect to the total study sample. We estimated both global prevalence and specific prevalence per age group, sex, educational level, morbidity and functionality. Calculation was made of the $95 \%$ confidence intervals $(95 \% \mathrm{CI})$ for the global and specific prevalence, together with prevalence adjusted for age and sex, using the European standard population [26] as a basis for adjustment (weighting: 36.4, 27.3, 18.2, 9.1 and 9.1 for age intervals of $65-69,70-74,75-79,80-84$ and $=$ 85 years, respectively).

The continuous variables were expressed as the mean \pm standard deviation (SD), while frequency distributions were used for the qualitative variables. Logistic regression analysis was used to explore the sociodemographic, functional and clinical factors independently associated with the presence of CIND/dementia. The enter method was used in a first step to include the adjusting variable (patient age and sex), followed in a second step by the stepwise method in application to the rest of the independent variables: years of education, educational level, Katz index, living with partner, restlessness, anxiety or depression, sleeping problems or insomnia, diabetes and Charlson comorbidity index. The dependent variable was cognitive impairment $(\mathrm{CI})$ (code 0 : no $\mathrm{CI}$; code 1 : presence of $\mathrm{CI}$ ), while in the case of the independent variables the reference groups were male sex, illiteracy, absence of diabetes, no insomnia, no depression, and living without a partner. Patient age, the Katz index, years of education and the Charlson comorbidity index were taken as continuous variables. The data were analyzed using the SPSS/PC+ version 18.0 statistical package (SPSS Inc., Chicago, IL, USA).

\section{Results}

Table 2 shows the raw, age-adjusted and age-and sexadjusted prevalence of CIND (48 participants, 14.7\%) 
Table 2 Crude, age-adjusted, and age- and sex-adjusted prevalence of dementia and cognitive impairment (CI).

\begin{tabular}{|c|c|c|c|c|c|c|c|c|c|}
\hline & \multicolumn{3}{|c|}{ Crude } & \multicolumn{2}{|c|}{ Age-adjusted $^{\mathrm{a}}$} & \multicolumn{2}{|c|}{ Age, sex ajusted ${ }^{a}$} & \multicolumn{2}{|c|}{ No. individuals ${ }^{b}$} \\
\hline & PP & PE & $95 \mathrm{Cl}$ & PP & $95 \mathrm{Cl}$ & PP & $95 \mathrm{Cl}$ & Count & $95 \mathrm{Cl}$ \\
\hline \multicolumn{10}{|c|}{ CI (Dementia+ CIND) } \\
\hline Male & $14 / 116$ & 12,1 & $6,1 \quad 18,0$ & 10,7 & $4,6-16,9$ & & & & \\
\hline Female & $48 / 211$ & 22,7 & $17,1-28,4$ & 19,1 & $12,9-25,2$ & & & & \\
\hline Both & $62 / 327$ & 19,0 & $14,7-23,2$ & 16,1 & $11,6-20,6$ & 14,9 & $10,6-19,2$ & 51 & $36-65$ \\
\hline \multicolumn{10}{|c|}{ Age-group } \\
\hline $65-69$ & $9 / 69$ & 13,0 & $5,1-21,0$ & & & & & & \\
\hline $70-74$ & $8 / 72$ & 11,1 & $3,9-18,4$ & & & & & & \\
\hline $75-79$ & $9 / 75$ & 12,0 & $4,6-19,4$ & & & & & & \\
\hline $80-84$ & $15 / 63$ & 23,8 & $13,3-34,3$ & & & & & & \\
\hline$\geq 85$ & $21 / 48$ & 43,8 & $29,7-57,8$ & & & & & & \\
\hline \multicolumn{10}{|l|}{ CIND } \\
\hline Male & $10 / 116$ & 8,6 & $3,5-13,7$ & 8,1 & $2,5-13,6$ & & & & \\
\hline Female & $38 / 211$ & 18,0 & $12,8-23,2$ & 15,1 & $9,6-20,6$ & & & & \\
\hline Both & $48 / 327$ & 14,7 & $10,8-18,5$ & 11,4 & $7,5-15,4$ & 11,6 & $7,7-15,5$ & 39 & $26-53$ \\
\hline \multicolumn{10}{|c|}{ Age-group } \\
\hline $65-69$ & $8 / 69$ & 11,6 & $4,0-19,1$ & & & & & & \\
\hline $70-74$ & $7 / 72$ & 9,7 & $2,9-16,6$ & & & & & & \\
\hline $75-79$ & $3 / 75$ & 4,0 & $0,0-8,4$ & & & & & & \\
\hline $80-84$ & $12 / 63$ & 19,0 & $9,4-28,7$ & & & & & & \\
\hline$\geq 85$ & $11 / 48$ & 22,9 & $11,0-34,8$ & & & & & & \\
\hline \multicolumn{10}{|c|}{ Dementia } \\
\hline Male & $4 / 116$ & 3,4 & $0,1-6,8$ & 2,7 & $0,0-5,3$ & & & & \\
\hline Female & $10 / 211$ & 4,7 & $1,9-7,6$ & 4,0 & $1,3-6,8$ & & & & \\
\hline Both & $14 / 327$ & 4,3 & $2,1-6,5$ & 3,4 & $1,5-5,3$ & 3,3 & $1,4-5,2$ & 11 & $5-18$ \\
\hline \multicolumn{10}{|c|}{ Age-group } \\
\hline $65-69$ & $1 / 69$ & 1,4 & $0,0-4,3$ & & & & & & \\
\hline $70-74$ & $1 / 72$ & 1,4 & $0,0-4,1$ & & & & & & \\
\hline $75-79$ & $6 / 75$ & 8,0 & $1,9-14,1$ & & & & & & \\
\hline $80-84$ & $3 / 63$ & 4,8 & $0,0-10,0$ & & & & & & \\
\hline$\geq 85$ & $3 / 48$ & 6,3 & $0,0-13,1$ & & & & & & \\
\hline
\end{tabular}

${ }^{a}$ Age standardization weights European Standard: $36.4,27.3,18.2,9.1$ and 9.1 for $65-69,70-74,75-79,80-84$ and $\geq 85$, respectively; sex standardization weight: 0.50 (sources: http://www.wmpho.org.uk/localprofiles/metadata.aspx?id=META_EUROSTD) [26];

${ }^{b}$ Estimated number of subjects in hundreds with de disease based on age- and sex-adjusted prevalence (Salamanca $\mathrm{h} \geq 65$ years 2009 estimated population: 34.020h. (source: Castilla and León Regional Health Service lists. CIND: cognitive impairment not dementia; $\mathrm{Cl}$, confidence interval; PE, prevalence point-estimate; $\mathrm{PP}$, crude prevalence ratio (cases divided by population).

and dementia (14 participants, 4.3\%). In total, 62 of the 327 participants studied (19.0\%) suffered from CI (CIND or dementia). On standardizing for age, the prevalence decreased similarly in men and women - the estimated adjusted prevalence being 16.1\% (95\%CI: 11.620.6), versus $14.9 \%$ when adjusted for age and sex. The prevalence of CIND and dementia increased with age ( $p$ $<0.001$ ), and women were seen to predominate among the individuals with CIND (79.16\%) and in those with dementia (71.42\%) (Figure 2). The 14 patients classified as presenting dementia had a mean age of 79.35 years $(\mathrm{SD}=7.33)$, and in 8 cases $(57.14 \%)$ the cause corresponded to Alzheimer's disease (AD), in 3 cases $(21.43 \%)$ to probable vascular disorders, and in 3 cases $(21.43 \%)$ to a mixture of factors.

Table 3 shows the characteristics of the 327 DERIVA study participants, stratified by cognitive status. Mean age was lower in the normal cognition group, while educational level was higher. The patients with CI had lower Charlson comorbidity scores. Figure 3 shows the prevalence of CIND according to educational level and the functional clinical and neuropsychological characteristics of the participants. The prevalence of CI among the illiterate participants was $34 \%$, versus $25.5 \%$ among 


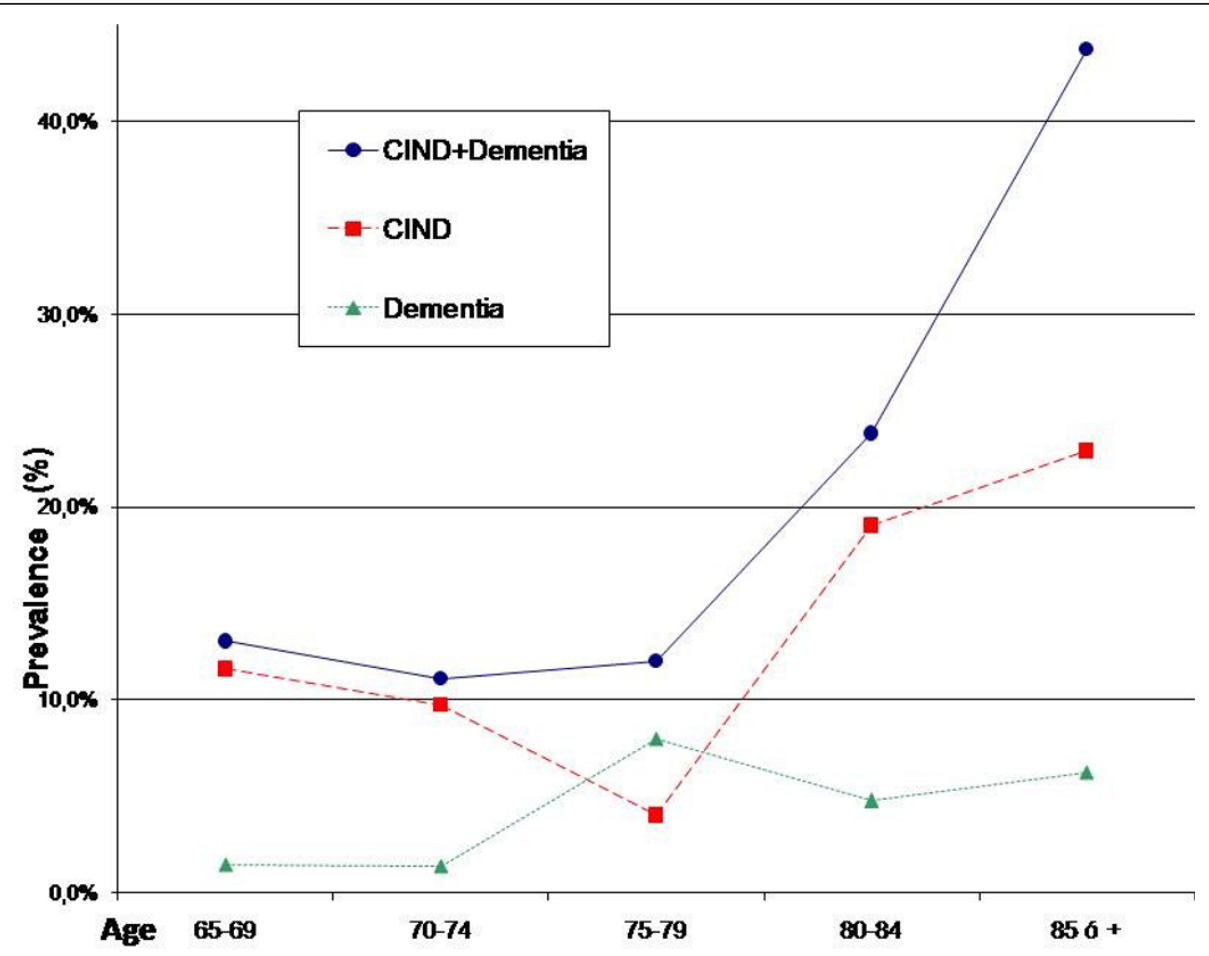

Figure 2 Crude, age-adjusted and age- and sex-adjusted prevalence of CIND and dementia.

the patients living without a partner. The prevalence of CI among the individuals with depression, insomnia, hypercholesterolemia or diabetes was over $27 \%$. In turn, $10.4 \%$ of the participants who were independent for their activities of daily living (ADLs) as assessed with the Katz index suffered from CI, versus $26.9 \%$ of the participants found to be dependent for two or more ADLs.

Significant predictor factors were found with the multivariate analyses: age $(\mathrm{OR}=1.08,95 \% \mathrm{CI}: 1.03-1.12)$, anxiety-depression $(\mathrm{OR}=3.47,95 \% \mathrm{CI}$ : 1.61-7.51), diabetes $(\mathrm{OR}=2.07,95 \% \mathrm{CI}: 1.02-4.18)$ and educational level $(\mathrm{OR}=0.79,95 \% \mathrm{CI}$ : 0.70-0.90) (Table 4).

\section{Discussion}

The observed prevalence of $14.7 \%$ for CIND and $4.3 \%$ for dementia implies a total of $19 \%$ of all people aged over 65 with CI in the city of Salamanca in 2009. The age-adjusted and age-and sex-adjusted overall prevalence (CIND or dementia) was $14.9 \%$ (95\%CI: 10.6-19.2). The prevalence of $\mathrm{CI}$ increased with age and decreased with increasing educational level. Although CI was more frequent among women and in people living without a partner, these characteristics were not significantly associated with CI risk. Significant risk factors were found with the multivariate analyses: age, anxiety-depression and diabetes, while years of education proved to be a protective factor.
Few population-based studies of CI have been published in Spain. Adequate comparisons are therefore difficult to make, though our data are within the lower range of other Spanish studies (13.8-35.2\%) [27-31] and European surveys $[1,10,32]$. A possible explanation for this relatively low prevalence may be the fact that our study was conducted in an urban setting. Large differences have been found among different Spanish regions. In this regard, Murcia yielded a CIND prevalence of $13.8 \%$ in the urban setting, versus $23.3 \%$ in the rural zone [27]. Nunes et al. [10], in an urban setting in the north of Portugal, reported a lower prevalence of CI (12.0\%), though these authors included a younger age group (55 to 79 years). The raw prevalence of CI found in our study is lower than the $22.2 \%$ reported for the United States $[24,33]$ or the $16.8 \%$ prevalence of CIND and $8 \%$ prevalence of dementia estimated for Canada [12].

In our study we took into account the most up-todate diagnostic criteria $[4,5,24]$ according to which it is considered that CIND can involve alteration in various higher cognitive functions, and not only in memory. Therefore, we should have obtained higher figures than if we had considered the criteria of Petersen et al [34]. On the other hand, however, the Katz ADL Index is less sensitive for assessing ADLs than for assessing more complex activities.

The literature offers more references to the prevalence of dementia, though consensus in this case is likewise 
Table 3 Sociodemographic, functional, clinical and neuropsychological characteristics of the participants according to cognitive impairment $(\mathrm{Cl})$.

\begin{tabular}{|c|c|c|c|}
\hline & $\begin{array}{c}\text { Healthy subjects } \\
\mathrm{N}(\%)\end{array}$ & $\begin{array}{c}\text { Subjects } \\
\text { with CI } \\
\mathrm{N}(\%)\end{array}$ & $\mathrm{p}$ \\
\hline Number of subjects $=327$ & 265(81.0) & $62(19.0)$ & \\
\hline Age $^{\#}$ & $75.46 \pm 6.83$ & $80.15 \pm 8.18$ & $<0.001$ \\
\hline Male & $75.26 \pm 6.52$ & $80.00 \pm 7.22$ & 0.013 \\
\hline Female & $75.58 \pm 7.04$ & $80.19 \pm 8.50$ & $<0.001$ \\
\hline Sex, n (\%) & & & 0.018 \\
\hline Male & $102(87.90)$ & $14(12.1)$ & \\
\hline Female & $163(77.30)$ & $48(22.7)$ & \\
\hline Years of education $^{\#}$ & $8.77 \pm 2.77$ & $6.93 \pm 2.81$ & $<0.001$ \\
\hline Educational level, n (\%) & & & $<0.001$ \\
\hline Iliterate & $68(66.0)$ & $35(34.00)$ & \\
\hline Primariy-Secondary education & $152(87.90)$ & $21(12.1)$ & \\
\hline Higher education & $45(91.8)$ & $4(8.2)$ & \\
\hline Regular occupation in his/her life, n (\%) & & & 0.137 \\
\hline Housewife & $68(74.70)$ & $23(25.30)$ & \\
\hline Full-time job & $174(84.10)$ & $33(15.90)$ & \\
\hline Others & $8(88.90)$ & $1(11.1)$ & \\
\hline Living with his/her partner, $\mathrm{n}(\%)$ & $158(86.30)$ & $25(13.7)$ & 0.007 \\
\hline Number of alive children (Mean \pm SD) & $2.41 \pm 1.87$ & $2.09 \pm 1.99$ & 0.265 \\
\hline Living with someone, $\mathrm{n}(\%)$ & & & 0.065 \\
\hline Alone & $56(90.30)$ & $6(9.70)$ & \\
\hline With one relative/friend & $149(81.0)$ & $35(19.00)$ & \\
\hline With at least with 2 people & $47(75.80)$ & $15(24.20)$ & \\
\hline With more than 2 people & $4(57.10)$ & $3(42.90)$ & \\
\hline \multicolumn{4}{|l|}{ Functionals } \\
\hline Activities of daily living (Katz Index): & & & $<0.001$ \\
\hline All preserved & $120(45.30)$ & $14(22.60)$ & \\
\hline Needs help on one activity & $49(18.10)$ & $10(16.10)$ & \\
\hline Needs help on bathing and other activity & $1(0.40)$ & $1(1.60)$ & \\
\hline Needs help on 6 activities & $0(0.00)$ & $2(3.20)$ & \\
\hline Needs help on at least 2 activities, but not classifiable on previous categories & $95(35.80)$ & $35(56.50)$ & \\
\hline \multicolumn{4}{|l|}{ Clinicals } \\
\hline Depression & $30(11.30)$ & $17(27.40)$ & 0.001 \\
\hline Insomnia & $41(15.50)$ & $17(27.40)$ & 0.027 \\
\hline Taking medicine for depression & $28(10.6)$ & $17(27.40)$ & 0.001 \\
\hline Taking medicine for insomnia & $38(14.30)$ & $15(24.20)$ & 0.058 \\
\hline Hypertension & $119(45.20)$ & $22(35.50)$ & 0.163 \\
\hline Dyslipidemia & $12(4.50)$ & $5(8.10)$ & 0.259 \\
\hline Diabetes Mellitus & $47(17.70)$ & $18(29.90)$ & 0.045 \\
\hline Charlson comorbidity Index (by age) & $3.90 \pm 1.46$ & $4.50 \pm 1.23$ & 0.004 \\
\hline \multicolumn{4}{|l|}{ Neuropsychologicals } \\
\hline MMSE $(0-30)^{\#}$ & $27.30 \pm 2.05$ & $19.12 \pm 4.74$ & $<0.001$ \\
\hline MMSE & & & $<0.001$ \\
\hline $0-13$ & $0(0.00)$ & $5(8.10)$ & \\
\hline $14-23$ & $3(1.10)$ & $43(69.40)$ & \\
\hline
\end{tabular}


Table 3 Sociodemographic, functional, clinical and neuropsychological characteristics of the participants according to cognitive impairment $(\mathrm{Cl})$. (Continued)

\begin{tabular}{|c|c|c|c|}
\hline $24-28$ & $162(61.10)$ & $3(4.80)$ & \\
\hline$>28$ & $81(30.60)$ & $0(0.00)$ & \\
\hline Benton temporal orientation test & $5.16 \pm 15.96$ & $38.00 \pm 35.66$ & $<0.001$ \\
\hline Clock drawing test\# & $5.97 \pm 1.52$ & $3.91 \pm 2.35$ & $<0.001$ \\
\hline Category Fluency\# & $15.90 \pm 5.04$ & $9.45 \pm 4.75$ & $<0.001$ \\
\hline 7 Minute Screen (Total)\# & $48.82 \pm 14.48$ & $67.38 \pm 31.87$ & $<0.001$ \\
\hline
\end{tabular}

Cl: cognitive impairment (CIND or dementia); MMSE: Minimental State Examination.

\#: Mean \pm Standard deviation

p: Statistically significant differences between the two groups

MMSE: Mini-Mental State Examination score.

lacking regarding the true figures applicable to Spain. Nevertheless, it has been suggested that the prevalence in this country is lower than in other regions of Europe. Our data point to an adjusted dementia prevalence in the city of Salamanca of $3.3 \%$, which is close to the lowest estimates both in Spain [2,6] and in Europe [32]. Crude dementia prevalence for elders aged 70 years and over range from 5\% in Murcia [27] to $17.2 \%$ in Pamplona [2].

Recent publications suggest that the number of individuals with CIND in the United States is about 70\% higher than the number with dementia. In the 71- to 79-year-old age group, $16 \%$ had CIND, whereas an additional $5 \%$ had dementia. A similar proportion was found in the recent Mexican Health and Aging Study [35], though the prevalence figures are slightly higher: $6.1 \%$ for CIND as against $28.7 \%$ for dementia. Another possible reason why these differences cannot be explained is the threshold set, since, as Seshadri et al. [36] pointed out, depending on where the differential threshold is placed, the percentages of CIND and dementia will vary. It should also be borne in mind that when a report is requested from an informant about the person's functional limitations, the prevalence is substantially lower $[2,6,11]$

It must be taken into account that the study was designed to determine the global prevalence of $\mathrm{CI}$, and that the estimation of dementia prevalence would require a larger sample. These results therefore must be viewed with caution. The study was carried out in a random sample of the population of the city that included people living in homes for the elderly, and since the prevalence of dementia in these institutions is higher than in the community [12] the possible associated bias has been avoided. However, the percentage distribution according to the most likely etiology coincides with the data of most other reports - Alzheimer's disease accounting for over one-half of the cases, followed by vascular dementia.

At present, evaluation of the existing data is the subject of even greater debate than the publication of new data $[2,24,34,35,37]$. It has been reported that the estimates of probable dementia are higher in surveys than in meta-analyses for the 65-84 year age interval, but similar among individuals aged 85 years and older [38]. In our study we obtained sufficient information in the context of a health survey, including evaluations of patient functionality and clinical and neuropsychological conditions, to determine the cognitive status of each participant [13]. Such information is therefore more relevant than that derived only from the application of a battery of tests. The diagnostic criteria employed are similar to those used in recent epidemiological studies $[33,36]$ with the purpose of obtaining results that can be compared with those collected in other settings, and also of examining the tendencies in disease prevalence in a single district in relation to morbidity among the elderly, healthcare, social support and economic resources. In accordance with the current recommendations for conducting epidemiological studies, on including patients with cognitive impairment, we placed priority on the inclusion of all individuals who possibly presented such impairment - since it was not our main objective to analyze the types or the severity of dementia. In other words, we placed greater emphasis on the use of those evaluating instruments affording greater sensitivity, at the cost of lesser specificity. Those surveys based only on the detection of dementia can underestimate the true incidence of neurodegenerative diseases in their milder stages. Considering all of the above, it is even more striking that the CI prevalences found are among the lowest published to date. There is no consensus regarding which functionality scales and neuropsychological batteries [39] are best suited to use in epidemiological studies in dementia, despite the fact that both elements have classically been used in diagnosing the disease [34]. It is exceptional for prevalence studies to specify how functionality has been evaluated [8], though we agree with Thomas et al. [40], who recommended the incorporation of functional disability data as a complement to studies estimating the 


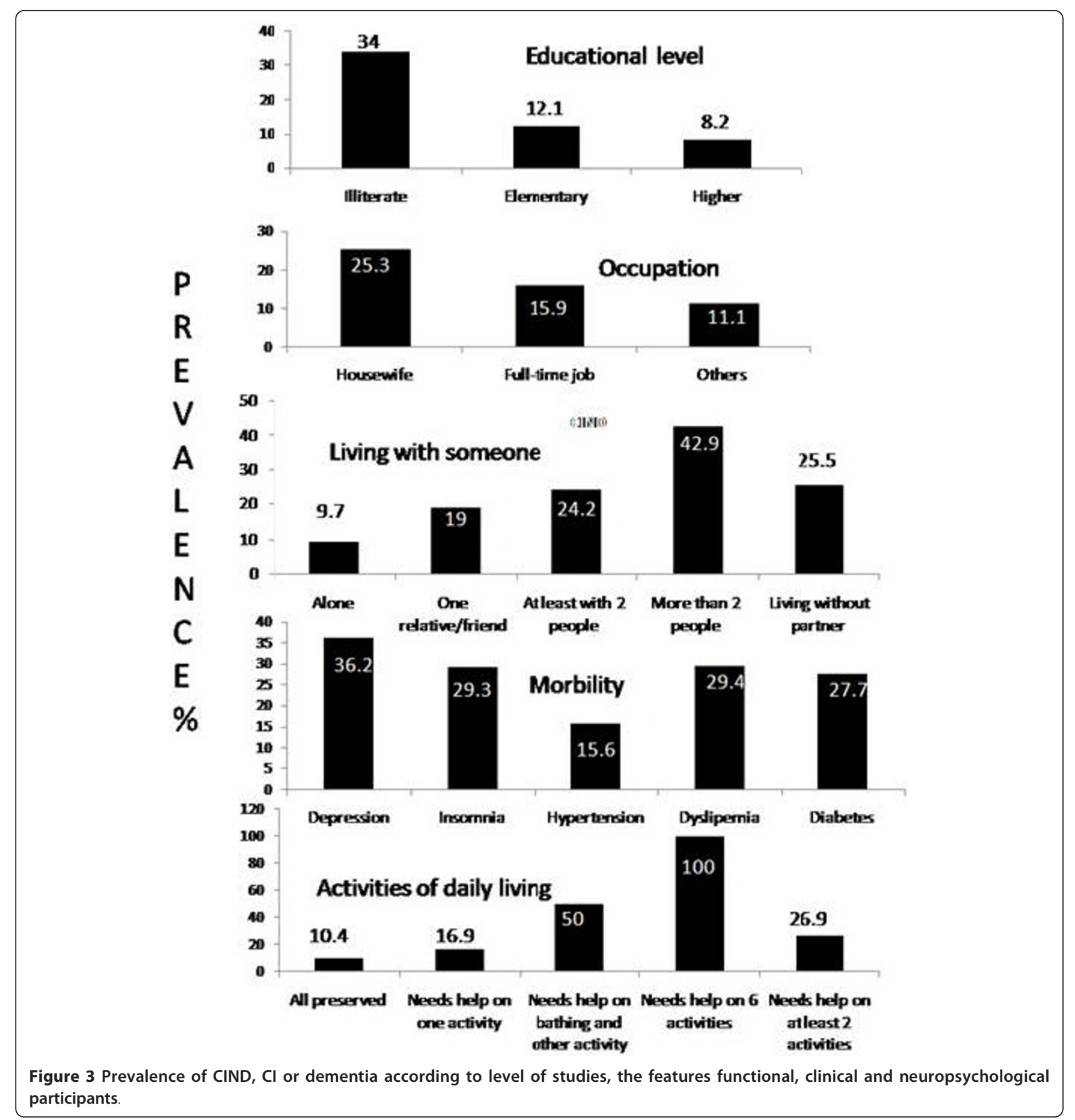

prevalence and severity of $\mathrm{CI}$ in the community. In our study, functionality was evaluated with the Katz ADL index, which is widely used to evaluate elderly people in an objective manner, and is therefore adequate for establishing comparisons among different populations. Among the participants of the DERIVA study, only $45.30 \%$ of those classified as not presenting CI, versus $22.60 \%$ of those classified as presenting CI, preserved functionality in all the areas evaluated by the Katz ADL index. Disability is common among people over 65 years of age; as a result, the way in which disability is evaluated exerts a strong influence when it is considered in the diagnosis of CI. Both the Lawton PSMS-IADL and the Katz scales remain widely used in psychosocial intervention research, and are easy to complete. The PSMSIADL is not as popular as the Katz index, but has an option for patient self-report. The Katz and PSMS-IADL have been used widely in anti-dementia drug studies 
Table 4 Variables associated with presenting cognitive impairment (Cl): OR and 95 confidence intervals for total CIND/dementia vs. Controls/Healthy.

\begin{tabular}{lccc}
\hline & $\mathbf{B}$ & $\mathbf{O R}(\mathbf{9 5} \% \mathbf{C I})$ & $\mathbf{P}$ \\
\hline Age & 0.07 & $1.08(1.03-1.12)$ & 0.00 \\
\hline Gender & 0.58 & $1.79(0.88-3.64)$ & 0.11 \\
\hline Years of education & -0.24 & $0.79(0.70-0.90)$ & 0.00 \\
\hline Depression-anxiety & 1.25 & $3.47(1.61-7.51)$ & 0.00 \\
\hline Diabetes & 0.73 & $2.07(1.02-4.18)$ & 0.04 \\
\hline
\end{tabular}

and in some psychosocial intervention studies in both North America and Europe [41,42]. Although the classical criteria of mild cognitive impairment (MCI) [34] excluded the presence of important functional deficits, the need to revise this approach has recently been suggested [43]- particularly when distinguishing between dementia and CIND, where different types of impairment are included [44]. Difficulties remembering appointments, telephone numbers, family meetings, holidays, medicines or domestic economics, or running businesses or filling out certain documents, can all be useful for suspecting early-stage CI [45]. Although less extensively studied, it is also necessary to consider statistical analyses of the results obtained with the different tests, taking into account that patient problems in obtaining better scores are not always attributable to CI. As an example, it has been described that 11 of the 30 items of the MMSE show high variability due to aspects unrelated to the degree of CI. Therefore, the MMSE would not be recommended as an instrument for use in screening for dementia among patients with Parkinson's disease [46].

\section{The importance of certain personal factors}

Our data coincide with those of practically all studies regarding the increase in $\mathrm{CI}$ with advancing age (Figure 2). It has been estimated that between 65 and 85 years of age, the prevalence doubles every 5.2 years, in an exponential manner [47]. However, there is no general agreement regarding prevalence in terms of patient sex. The condition is rarely associated with the male sex [48], while in contrast many studies have associated dementia with the female sex $[2,29,31,49,50]$, since women predominate in descriptive studies, and a correlation is found in the bivariate analyses, in accordance with our own observations. However, on considering other variables such as age, educational level or comorbidity, this relationship disappears. Our data would support the idea that dementia is not associated with women $[1,25,27,33,47]$. In coincidence with our own study, many authors $[7,33,51]$ have described an inverse relationship between the prevalence of $\mathrm{CI}$ and a lower educational level. Thus, it has been suggested that these differences could be related to certain biological mechanisms that would be responsible for this association $[8,27,29,52,53]$. However, a recent epidemiological study based on 875 necropsies revealed no protective effect of the years of education received in early stages in life in relation to the accumulation of neurodegenerative or vascular pathologies of the brain [54]. Even so, it has been suggested that when the disease affects people with higher educational level, the manifestations are milder, being mitigated by a greater coping capacity thereby postponing their consequences for a period of time. It remains to be clarified whether educational levels developed in later periods in life may or may not affect the development of dementia. In an attempt to offer information on this issue, we analyzed the type of regular professional activity of the DERIVA study patients before retirement, though no relationships were found. Perhaps a different classification of activity, analyzing those which may contribute most to intellectual development, could help identify a relationship. Regarding the family situation, we found that those participants living with their partner showed a $13.7 \%$ lower prevalence of CI than those living without a partner $(\mathrm{p}=$ 0.007). This is in agreement with the observations of Helmer [55], who found single individuals to have a greater risk of suffering dementia than married people. In our case there were no differences related to the fact of living alone or with one or more people, in terms of the prevalence of CI. As ours is a cross-sectional study, however, neither of these characteristics offers information for clarifying whether the current situation is a consequence of or a risk factor for the development of CI.

Many chronic illnesses can be found in elderly people. The Charlson score was greater among the individuals with $\mathrm{CI}(\mathrm{p}=0.004)$, though the multivariate analysis did not find it to behave as a risk factor for CI. The association between diabetes $(p=0.045)$ and dementia has already been described in classic studies [52], though it must be mentioned that while arterial hypertension is accepted as being more closely associated with stroke $[31,51]$, diabetes is the disease found to be associated with $\mathrm{CI}$ in the logistic regression analyses. The association between $\mathrm{CI}$ and diabetes, as well as the absence of an association with arterial hypertension and hypercholesterolemia, coincide with the findings in another Spanish region [56]. It appears that brain damage would be related to vascular mechanisms [33,37], and since the prevalence of these cardiovascular diseases is not homogeneous in all regions, they should be considered in CI prevalence studies with a view to establishing comparisons. People with CI more often have sleeping problems $(\mathrm{p}=0.027)$ and anxiety-depression $(\mathrm{p}<0.001)$, though only the latter was seen to behave as a CI risk factor in the multivariate analysis. In coincidence with Johansson 
et al. [57], we found an association between psychological stress and $\mathrm{CI}$, though in the study by the mentioned authors this association was detected in middle-aged women.

Among the limitations of our study, mention must be made of the lack of consensus on the precise criteria involved in making comparisons between different epidemiological studies. Another common and important limitation in studies of this kind is the possible loss of the more seriously deteriorated individuals, since it has been shown that those people who refuse to participate are more likely to have more seriously impaired cognitive function [58] - a situation which may introduce bias and alter the prevalence data obtained. A further limitation of the study is that since the evaluations were carried out by four different psychologists, inter-observer reliability may be affected. However, each evaluation was followed by an appraisal of the interview with a view to tests correction and the reduction of possible bias. Among the strengths of the study, we should mention the inclusion of a representative sample from the city of Salamanca, as well the proposal to incorporate functional evaluation and the clinical processes influencing the prevalence of CI [5]. The study cohort would permit a longitudinal evaluation of CIND, and the longterm results may contribute to identifying the characteristics of those individuals who develop dementia.

\section{Conclusions}

The observed raw prevalence of CI was 19\% (14.9\% after adjusting for age and sex), and corresponds to the lower range of the prevalence estimated at both national and international level. Older age and the presence of diabetes and anxiety-depression increased the risk of CI, while higher educational level reduced the risk.

\section{List of abbreviations}

AD: Alzheimer's disease; BADL: basic activities of daily living; $\mathrm{Cl}$ : Cognitive Impairment; CIND: Cognitive impairment - no dementia.

\section{Acknowledgements}

This project was supported by the INFOSALUD Foundation, Castilla-León Health Service (GRS 270/A/08 and BIO39/SA04/10), ISCIII (RD06/018/27), and Vicente- García Corselas Foundation (University of Salamanca).

\section{Author details}

'Primary care research unit of La Alamedilla Health Center, Castilla y León Health Service- SACYL, Salamanca, Spain. 'Department of Basic Psychology, Psychobiology and Behavioral Sciences Methodology. Faculty of Psychology. University of Salamanca. Spain. ${ }^{3}$ Department of Statistics. Faculty of Medicine. University of Salamanca. Spain.

\section{Authors' contributions}

Conception of the idea for the study: ERS, RGG, LGO, MGM and MVP. Development of the protocol and organization: ERS, SMS, CPA and AEH. Participated in the design of the study and performed the statistical analysis: ERS, SMS, CPA and AEH. Writing of the manuscript: ERS, SMS CPA and LGO. All the authors have read the draft critically, so as to make contributions, and have approved the final text. The project was developed by the Primary Care Research Unit at La Alamedilla Health Centre, Salamanca. Spain.

\section{Competing interests}

The authors declare that they have no competing interests.

Received: 12 August 2011 Accepted: 17 November 2011

Published: 17 November 2011

\section{References}

1. De Ronchi D, Berardi D, Menchetti M, Ferrari G, Serretti A, Dalmonte E, Fratiglioni L: Occurrence of cognitive impairment and dementia after the age of 60: a population-based study from Northern Italy. Dement Geriatr Cogn Disord 2005, 19(2-3):97-105.

2. de Pedro-Cuesta J, Virues-Ortega J, Vega S, Seijo-Martinez M, Saz P, Rodriguez F, Rodriguez-Laso A, Rene R, de las Heras SP, Mateos R, MartinezMartin P, Manubens JM, Mahillo-Fernandez I, Lopez-Pousa S, Lobo A, Regla JL, Gascon J, Garcia FJ, Fernandez-Martinez M, Boix R, BermejoPareja F, Bergareche A, Benito-Leon J, de Arce A, del Barrio JL: Prevalence of dementia and major dementia subtypes in Spanish populations: a reanalysis of dementia prevalence surveys, 1990-2008. BMC Neurol 2009, 9:55.

3. INE: Instituto Nacional de Estadística: Datos de población en España. [http://www.ine.es], (15/05/2011).

4. McKhann GM, Knopman DS, Chertkow H, Hyman BT, Jack CR Jr, Kawas CH, Klunk WE, Koroshetz WJ, Manly JJ, Mayeux R, Mohs RC, Morris JC, Rossor MN, Scheltens P, Carrillo MC, Thies B, Weintraub S, Phelps CH: The diagnosis of dementia due to Alzheimer's disease: recommendations from the National Institute on Aging-Alzheimer's Association workgroups on diagnostic guidelines for Alzheimer's disease. Alzheimers Dement 2011, 7(3):263-269.

5. Albert MS, DeKosky ST, Dickson D, Dubois B, Feldman HH, Fox NC, Gamst A Holtzman DM, Jagust WJ, Petersen RC, Snyder PJ, Carrillo MC, Thies B, Phelps CH: The diagnosis of mild cognitive impairment due to Alzheimer's disease: recommendations from the National Institute on Aging-Alzheimer's Association workgroups on diagnostic guidelines for Alzheimer's disease. Alzheimers Dement 2011, 7(3):270-279.

6. Virues-Ortega J, de Pedro-Cuesta J, Vega S, Seijo-Martinez M, Saz P, Rodriguez F, Rodriguez-Laso A, Rene R, de Las Heras SP, Mateos R, Martinez-Martin P, Mahillo-Fernandez I, Lopez-Pousa S, Lobo A, Regla JL, Gascon J, Garcia FJ, Fernandez-Martinez M, Boix R, Bermejo-Pareja F, Bergareche A, Sanchez-Sanchez F, de Arce A, del Barrio JL: Prevalence and European comparison of dementia in a $>/=75$-year-old composite population in Spain. Acta Neurol Scand 2011, 123(5):316-324.

7. Gascon-Bayarri J, Rene R, Del Barrio JL, De Pedro-Cuesta J, Ramon JM, Manubens JM, Sanchez C, Hernandez M, Estela J, Juncadella M, Rubio FR: Prevalence of dementia subtypes in El Prat de Llobregat, Catalonia, Spain: the PRATICON study. Neuroepidemiology 2007, 28(4):224-234.

8. Escudero Sanchez C, Garcia Carmona R, Ibanez Colas A, Lopez Lopez MA, Hidalgo Garcia-Consuegra MA, Perez Juarez A, Salan Garcia M, Utrilla Bermejo F: [Cognitive deficit, its prevalence and associated factors in the population over 74]. Aten Primaria 1999, 24(6):326-331.

9. Ankri J, Poupard M: [Prevalence and incidence of dementia among the very old. Review of the literature]. Rev Epidemiol Sante Publique 2003, 51(3):349-360.

10. Nunes B, Silva RD, Cruz VT, Roriz JM, Pais J, Silva MC: Prevalence and pattern of cognitive impairment in rural and urban populations from Northern Portugal. BMC Neurol 2010, 10:42.

11. Wilson R, David R, Weir D, Leurgans S, Evans D, Hebert L, Langa K, Plassman B, Small B, Bennett D: Sources of variability in estimates of the prevalence of Alzheimer's disease in the United States. Alzheimers Dement 2011, 7:74-79.

12. Graham JE, Rockwood K, Beattie BL, Eastwood R, Gauthier S, Tuokko H, McDowell I: Prevalence and severity of cognitive impairment with and without dementia in an elderly population. Lancet 1997, 349(9068):1793-1796.

13. Grau Fibla G, Eiroa Patino P, Cayuela Dominguez A: [Spanish version of the OARS Multidimensional Functional Assessment Questionnaire: crosscultural adaptation and validity measurement]. Aten Primaria 1996, 17(8):486-495 
14. Charlson M, Szatrowski TP, Peterson J, Gold J: Validation of a combined comorbidity index. Journal of Clinical Epidemiology 1994, 47(11):1245-1251.

15. Wallace MS: Mary Katz Index of Independence in Activities of Daily Living (ADL). Assisted Living Consult 2008, 2:21-22.

16. Folstein MF, Folstein SE, McHugh PR: "Mini-mental state". A practical method for grading the cognitive state of patients for the clinician. $J$ Psychiatr Res 1975, 12(3):189-198.

17. Escribano-Aparicio MVP-DM, García-García FJ, Pérez-Martín A, Romero L, Ferrer G, Martín-Correa E, Sánchez-Ayala MI: Validación del MMSE de Folstein en una población española de bajo nivel educativo. Rev Esp Geriatr Gerontol 1999, 34(6):319-326.

18. Solomon PR, Hirschoff A, Kelly B, Relin M, Brush M, DeVeaux RD Pendlebury WW: A 7 minute neurocognitive screening battery highly sensitive to Alzheimer's disease. Arch Neurol 1998, 55(3):349-355.

19. del Ser Quijano T, Sanchez Sanchez F, Garcia de Yebenes MJ, Otero Puime A, Zunzunegui MV, Munoz DG: [Spanish version of the 7 Minute screening neurocognitive battery. Normative data of an elderly population sample over 70]. Neurologia 2004, 19(7):344-358.

20. Benton A: Contributions to Neuropsychological Assessment. New York, NY: Oxford University Press Inc; 1983.

21. Grober E, Buschke H, Crystal H, Bang S, Dresner R: Screening for dementia by memory testing. Neurology 1988, 38(6):900-903.

22. Freedman M LL, Kaplan E, Winocur G, Shulman KI, Delis D: Clock Drawing: A Neuropsychological Analysis. New York, NY: Oxford University Press Inc 1994.

23. Goodglass H KE: Evaluación de la afasia y de trastornos relacionados. Madrid: Panamericana; 1986.

24. Brookmeyer R, Evans DA, Hebert L, Langa KM, Heeringa SG, Plassman BL, Kukull WA: National estimates of the prevalence of Alzheimer's disease in the United States. Alzheimers Dement 2011, 7(1):61-73.

25. Plassman BL, Langa KM, Fisher GG, Heeringa SG, Weir DR, Ofstedal MB, Burke JR, Hurd MD, Potter GG, Rodgers WL, Steffens DC, McArdle JJ, Willis RJ, Wallace RB: Prevalence of cognitive impairment without dementia in the United States. Ann Intern Med 2008, 148(6):427-434.

26. WMPHO: West Midlands Public Health Observatory.The European Standard Population.[http://www.wmpho.org.uk/localprofiles/metadata. aspx?id=META_EUROSTD].

27. Gavrila D, Antunez C, Tormo MJ, Carles R, Garcia Santos JM, Parrilla G, Fortuna L, Jimenez J, Salmeron D, Navarro C: Prevalence of dementia and cognitive impairment in Southeastern Spain: the Ariadna study. Acta Neurol Scand 2009, 120(5):300-307.

28. Bufill E, Bartes A, Moral A, Casadevall T, Codinachs M, Zapater E, Rovira JC, Perez R, Roura P, Blesa R: [Prevalence of cognitive deterioration in people over 80-years-old: COGMANLLEU study]. Neurologia 2009, 24(2):102-107.

29. Graciani A, Banegas JR, Guallar-Castillon P, Dominguez-Rojas V, RodriguezArtalejo F: Cognitive assessment of the non-demented elderly community dwellers in Spain. Dement Geriatr Cogn Disord 2006, 21(2):104-112.

30. Limon Ramirez E, Argimon Pallas JM, Vila Domenech J, Abos Pueyo T, Cabezas Pena C, Vinyoles Bargallo E: [Detection of cognitive impairment in the population of persons older than 64 years: first phase of the Cuida'l project]. Aten Primaria 2003, 32(1):6-12.

31. Millan-Calenti JC, Tubio J, Pita-Fernandez S, Gonzalez-Abraldes I, Lorenzo T, Maseda A: Prevalence of cognitive impairment: effects of level of education, age, sex and associated factors. Dement Geriatr Cogn Disord 2009, 28(5):455-460.

32. Ferri $C P$, Prince $M$, Brayne $C$, Brodaty $H$, Fratiglioni $L$, Ganguli $M$, Hall $K$, Hasegawa K, Hendrie $H$, Huang $Y$, Jorm A, Mathers C, Menezes PR, Rimmer E, Scazufca M: Global prevalence of dementia: a Delphi consensus study. Lancet 2005, 366(9503):2112-2117.

33. Plassman BL, Langa KM, Fisher GG, Heeringa SG, Weir DR, Ofstedal MB, Burke JR, Hurd MD, Potter GG, Rodgers WL, Steffens DC, Willis RJ, Wallace RB: Prevalence of dementia in the United States: the aging, demographics, and memory study. Neuroepidemiology 2007, 29(12):125-132.

34. Petersen RC, Roberts RO, Knopman DS, Boeve BF, Geda YE, Ivnik RJ, Smith GE, Jack CR Jr: Mild cognitive impairment: ten years later. Arch Neurol 2009, 66(12):1447-1455.

35. Mejia-Arango S, Gutierrez LM: Prevalence and incidence rates of dementia and cognitive impairment no dementia in the Mexican population: data from the Mexican Health and Aging Study. J Aging Health 2011, 23(7):1050-1074.

36. Seshadri S, Beiser A, Au R, Wolf PA, Evans DA, Wilson RS, Petersen RC, Knopman DS, Rocca WA, Kawas CH, Corrada MM, Plassman BL, Langa KM, Chui HC: Operationalizing diagnostic criteria for Alzheimer's disease and other age-related cognitive impairment-Part 2. Alzheimers Dement 2011, 7(1):35-52.

37. Shin HY, Chung EK, Rhee JA, Yoon JS, Kim JM: [Prevalence and related factors of dementia in an urban elderly population using a new screening method]. J Prev Med Public Health 2005, 38(3):351-358.

38. Anstey KJ, Burns RA, Birrell CL, Steel D, Kiely KM, Luszcz MA: Estimates of probable dementia prevalence from population-based surveys compared with dementia prevalence estimates based on meta-analyses. BMC Neurol 2010, 10:62.

39. Maruta C, Guerreiro M, de Mendonca A, Hort J, Scheltens P: The use of neuropsychological tests across Europe: the need for a consensus in the use of assessment tools for dementia. Eur J Neurol 2011, 18(2):279-285.

40. Thomas VS, Darvesh S, MacKnight C, Rockwood K: Estimating the prevalence of dementia in elderly people: a comparison of the Canadian Study of Health and Aging and National Population Health Survey approaches. Int Psychogeriatr 2001, 13(Supp 1):169-175.

41. Moniz-Cook E, Vernooij-Dassen M, Woods R, Verhey F, Chattat R, De Vugt M, Mountain G, O'Connell M, Harrison J, Vasse E, Droes RM, Orrell M: A European consensus on outcome measures for psychosocial intervention research in dementia care. Aging Ment Health 2008, 12(1):14-29.

42. Olazaran J, Reisberg B, Clare L, Cruz I, Pena-Casanova J, Del Ser T, Woods B, Beck C, Auer S, Lai C, Spector A, Fazio S, Bond J, Kivipelto M, Brodaty H, Rojo JM, Collins H, Teri L, Mittelman M, Orrell M, Feldman HH, Muniz R: Nonpharmacological therapies in Alzheimer's disease: a systematic review of efficacy. Dement Geriatr Cogn Disord 2010, 30(2):161-178.

43. Brown PJ, Devanand DP, Liu X, Caccappolo E: Functional Impairment in Elderly Patients With Mild Cognitive Impairment and Mild Alzheimer Disease. Arch Gen Psychiatry 2011, 68(6):617-626.

44. Bangen KJ, Jak AJ, Schiehser DM, Delano-Wood L, Tuminello E, Han SD, Delis DC, Bondi MW: Complex activities of daily living vary by mild cognitive impairment subtype. J Int Neuropsychol Soc 2010, 16(4):630-639.

45. Binegar DL, Hynan LS, Lacritz LH, Weiner MF, Cullum CM: Can a direct IADL measure detect deficits in persons with MCI? Curr Alzheimer Res 2009, 6(1):48-51.

46. Prieto G, Delgado AR, Perea MV, Ladera V: Scoring neuropsychological tests using the Rasch model: an illustrative example with the ReyOsterrieth Complex Figure. Clin Neuropsychol 2010, 24(1):45-56.

47. Jorm AF, Jolley D: The incidence of dementia: a meta-analysis. Neurology 1998, 51(3):728-733.

48. Henao-Arboleda E, Aguirre-Acevedo DC, Munoz C, Pineda DA, Lopera F: [Prevalence of mild cognitive impairment, amnestic-type, in a Colombian population]. Rev Neurol 2008, 46(12):709-713.

49. Yaffe K, Middleton LE, Lui LY, Spira AP, Stone K, Racine C, Ensrud KE, Kramer $\mathrm{JH}$ : Mild cognitive impairment, dementia, and their subtypes in oldest old women. Arch Neurol 2011, 68(5):631-636.

50. Fernandez M, Castro-Flores J, Perez-de las Heras S, MandalunizLekumberri A, Gordejuela M, Zarranz J: [Prevalence of dementia in the elderly aged above 65 in a district in the Basque Country]. Rev Neurol 2008, 46(2):89-96.

51. De Ronchi D, Palmer K, Pioggiosi $P$, Atti AR, Berardi D, Ferrari B, Dalmonte $E$, Fratiglioni $L$ : The combined effect of age, education, and stroke on dementia and cognitive impairment no dementia in the elderly. Dement Geriatr Cogn Disord 2007, 24(4):266-273.

52. Ott A, Breteler MM, van Harskamp F, Claus JJ, van der Cammen TJ, Grobbee DE, Hofman A: Prevalence of Alzheimer's disease and vascular dementia: association with education. The Rotterdam study. BMJ 1995, 310(6985):970-973

53. Stern Y, Gurland B, Tatemichi TK, Tang MX, Wilder D, Mayeux R: Influence of education and occupation on the incidence of Alzheimer's disease. JAMA 1994, 271(13):1004-1010.

54. Brayne C, Ince PG, Keage HA, McKeith IG, Matthews FE, Polvikoski T, Sulkava R: Education, the brain and dementia: neuroprotection or compensation? Brain 2010, 133(Pt 8):2210-2216.

55. Helmer C: Dementia and marital status at midlife and late life. BMJ 2009, 339:b1690. 
56. Fernandez Martinez M, Castro Flores J, Perez de Las Heras S, Mandaluniz Lekumberri A, Gordejuela Menocal M, Zarranz Imirizaldu JJ: Risk factors for dementia in the epidemiological study of Munguialde County (Basque Country-Spain). BMC Neurol 2008, 8:39.

57. Johansson L, Guo X, Waern M, Ostling S, Gustafson D, Bengtsson C, Skoog I: Midlife psychological stress and risk of dementia: a 35-year longitudinal population study. Brain 2010, 133(Pt 8):2217-2224.

58. Matthews FE, Chatfield M, Freeman C, McCracken C, Brayne C: Attrition and bias in the MRC cognitive function and ageing study: an epidemiological investigation. BMC Public Health 2004, 4:12.

\section{Pre-publication history}

The pre-publication history for this paper can be accessed here: http://www.biomedcentral.com/1471-2377/11/147/prepub

doi:10.1186/1471-2377-11-147

Cite this article as: Rodríguez-Sánchez et al:: Prevalence of cognitive

impairment in individuals aged over 65 in an urban area: DERIVA study. BMC Neurology 2011 11:147.

\section{Submit your next manuscript to BioMed Central} and take full advantage of:

- Convenient online submission

- Thorough peer review

- No space constraints or color figure charges

- Immediate publication on acceptance

- Inclusion in PubMed, CAS, Scopus and Google Scholar

- Research which is freely available for redistribution

Submit your manuscript at www.biomedcentral.com/submit 